\title{
New Development of Classification of Knowledge and Cognitive Targets
}

\author{
Bingqian Chen \\ School of Foreign Languages \\ China West Normal University \\ Nanchong, China 637002
}

\begin{abstract}
The famous American cognitive psychologist Anderson divided knowledge into declarative knowledge and procedural knowledge from the perspective of cognitive psychology, determining the basic classification of knowledge. On this basis, the revised edition of Bloom's taxonomy of educational objectives has made a new revision of the classification of knowledge and cognitive goals from the knowledge dimension and cognitive dimension, and proposed a two-dimensional teaching goal based on the knowledge dimension and the cognitive dimension.
\end{abstract}

Keywords-declarative knowledge; procedural knowledge; a revised edition of Bloom's taxonomy of educational objectives

\section{INTRODUCTION}

What exactly is knowledge, what knowledge is most valuable in education, and what level of knowledge should students require? There is no unified answer to this series of questions. However, these issues have important guiding role in education. The definition of knowledge in China is generally defined from the perspective of philosophy. For example, the description of knowledge in the Bible of Game Theory is "knowledge refers that identifying the correctness of entity and nature of all things." China Macropaedia - Education" expresses "knowledge" as: "The socalled knowledge, in terms of the content it reflects, is a reflection of the attributes and connections of objective things, and is a subjective reflection of the objective world in the human brain. As far as its reflection forms are concerned, it is sometimes expressed as the perceptual perception or representation of the subject, which belongs to the perceptual knowledge, and sometimes expressed as the concept or law of things, which belongs to the rational knowledge". From this definition, we can see that knowledge is the product of the unity of subject and object. It comes from the external world, so knowledge is objective; however, knowledge itself is not an objective reality. It is a reflection of the characteristics and connections of things in the human brain. It is a subjective representation of objective things. Knowledge is produced through the reflection of the human brain based on the interaction between the subject and the object.

\section{L.W.ANDERSON'S KNOWLEDGE CLASSIFICATION}

The famous American cognitive psychologist Anderson divides the knowledge into two kinds: declarative knowledge and procedural knowledge. He starts from the nature of knowledge, that is, to study human cognition from the perspective of knowledge representation. He believes that declarative knowledge and procedural knowledge are essentially different. The former is mainly characterized by propositional networks or schemata. It is knowledge about the "what" is fact; the latter is mainly expressed in the form of production (also known as generative knowledge), which is about the knowledge of a certain operational activity. For the psychological processes that these two types of knowledge are acquired, their representation in the individual's mind, and their maintaining and activating characteristics are very different. According to the classification of knowledge, learning results can be divided into declarative knowledge learning and procedural knowledge learning.

\section{A. Declarative Knowledge}

Declarative knowledge is about the state of things people know. It can be stated and described by people. And it answers the question of "what the world is". For example, "where are the four capitals of China?""What is the cause of the second world war?". It includes propositions, appearances, and linear sorting.

(1) Propositions are the basic unit of knowledge and information processing. A proposition is equivalent to a concept. And many sentences just express a concept and contain only one proposition. On the contrary, some sentences express multiple ideas and contain more propositions. Declarative knowledge is characterized by a proposition or proposition network. Propositions are not linguistically meaningful words and sentences. Words and sentences are merely forms of ideas, while propositions are conceptual kernels. People's learning should mainly focus on propositions. Propositions are units of meaning, thought, and ideas. Several propositions that are connected to each other can form a network of propositions.

The knowledge in the human brain is stored by establishing a relationship with other knowledge. Only the knowledge stored in a certain network system can be effectively extracted and used. In the human brain, a large amount of information is stored in the form of propositional networks. Most of the propositions in this form are dormant. The propositions activated by external stimuli exist in working memory, which is what is currently being considered. These activated 
propositions will activate the propositions that are related to them, allowing them to enter into working memory, which acts as a step-by-step process of thinking. This process is called the expansion of activation. In the process of obtaining declarative knowledge, new propositions enter the working memory and become clues for retrieving existing relevant knowledge, which will activate relevant propositions in the original proposition network. The new proposition and the original proposition that has been activated enter the working memory at the same time, and then there is finishing. Through finishing, the old and new propositions are linked together, and new propositions can also be generated. These all will enter into the proposition network and are stored together. This is the process of obtaining declarative knowledge. The extraction of declarative knowledge first needs problems. The problems can be raised by the outside world or the learner himself. Then, the problem will be transformed into an internal propositional representation, and become a clue to activate relevant knowledge, and then activate the related propositions in the original proposition network by diffusing activation. If the active proposition can answer the question raised, the extraction is over; if the active proposition does not answer the question and there is time to retrieve it, then the proliferation of activation will continue until the right answer is found.

(2) Representation is the form of non-verbal treatment or retention of knowledge. In many cases, when we imagine an object or situation that is not in front of us, we will experience their appearance. For this reason, people often say "it looks like they are in the mind."From this point of view, there are at least two ways to representative declarative knowledge in memory: The one is the previously mentioned propositions based on the abstract meaning of things. They do not need to retain the object's perceptual information; the other one is currently mentioned representation that is based on the perception of things. They generally retain the perceptual characteristics of things. The representations can represent changing information and can withstand the various psychological operations imposed on them.

(3) Linear ordering is the encoding of a linear sequence of a series of elements. For example, if a person is born in a multichild family, he will express his siblings according to the characteristics of the order of birth. This situation is the sequential coding of a group of elements by a certain feature. The difference between linear sorting and propositions is that the proposition preserves only the basic semantic relations between the elements mentioned in the proposition, but does not necessarily order the elements; the difference between linear ordering and representation is that representation preserves the interval relationship between perceptual features, and linear ordering arranges the order of a group of elements from beginning to end, but does not involve the size of the interval between each element.

\section{B. Procedural Knowledge}

Procedural knowledge is characterized by a production system. Production refers to the connection of conditions and actions, that is, a rule that produces an action under certain conditions. It consists of a conditional item "if" and an action item "then". The reason that the human brain can perform calculations, reasoning, and problem solving is because people learn and store a series of rules in their minds in the form of "If-Then". This rule is called production. From the point of view of production and propositional form, the connection of "condition-action" is consistent with that of "stimulusreaction", but the conditions and actions in production can be internal events, not necessarily external stimulation and reaction. The difference between production and proposition can further demonstrate the difference between declarative knowledge and procedural knowledge. The declarative knowledge stored in the form of propositions is the basis for the reproduction of information, and the procedural knowledge based on productive storage is the basis for operating information capabilities. Just as multiple propositions will form a propositional network, multiple productions can also form a production system.

Although production systems can be used to characterize procedural knowledge, people do not realize every step in the use of procedural knowledge. This is the automation of procedural knowledge. The production system can exactly represent the characteristics of this automation, that is, the connection between conditions and actions can be automated in the unconscious. The production is assumed to be stored in long-term memory. As soon as it meets the conditions that in line with it, it is activated and sends out commands to do certain actions. Automation is an advantage of the human information processing system.

Although cognitive psychologists infer that there should be these two kinds of knowledge based on the difference in knowledge of human behavior, this does not mean that there is a lack of internal connection and interaction between the two types of knowledge. Of course, for some of the knowledge in certain disciplines, we ultimately only need students to be able to recall and state; however, for most subject areas, educators naturally do not want students to stay on the level of speaking only, but hope that knowledge can be translated into effective guidelines to guide students' actions. From a cognitive psychology point of view, there must be a process to go through from statements to actions, if you don't know how to state knowledge clearly, then it is impossible to achieve a change to action. Therefore, declarative knowledge is the foundation or starting stage of procedural knowledge. Conversely, the acquisition of procedural knowledge further promotes the learning of declarative knowledge.

\section{A NEW VERSION OF BLOOM'S TAXONOMY OF EDUCATIONAL OBJECTIVES}

Bloom's taxonomy of educational objectives has been widely used in the education sector for the past 40 years, which is a clear indication that it fills a gap. But with the new discoveries in psychology research and the introduction of new psychological theories, publishers publishing this book on target classification feel it necessary to make people re-notice the value of Bloom's taxonomy of educational objectives. And as an open theory, it is necessary to absorb new psychological achievements. So 40 years later there was the idea of revising Bloom's taxonomy of educational objectives. In 1994, headed by Longman Press, L.W. Anderson and DR Krathwohl organized an outstanding team of authors to critically analyze 
Bloom's taxonomy of educational objectives and reflected on the contribution of objectives taxonomy to educational theory and practice. On this basis, the book "Bloom's Taxonomy of Educational Objectives - A Review of 40 Years" was published, which was actually preparing for the 56th edition revision of Bloom's taxonomy of educational objectives. Seven years later, in 2001, the book "Classification Theory for Learning, Teaching, and Assessment - A Revision of Bloom's Taxonomy of Educational Objectives" was finally published. The publication of the book marked Bloom's taxonomy of educational objectives had made new improvements along with the development of psychological theory.

Anderson, a well-known expert on curriculum theory and education, Craswall, who once worked with Broom on the development of the taxonomy of educational objectives, Meyer, the famous educational psychologist, and Alesa, a test and evaluation expert are all participated in this work. According to the long-term application of Bloom's taxonomy of educational objectives, combined with the implementation of the education reform on curriculum standards in the United States, "The Taxonomy for Learning, Teaching, and Evaluation --- Revision of Bloom's Taxonomy of Educational Objectives", which started brewing in the mid-1990s, was completed and published in 2001.

The editors of the revised taxonomy of educational objectives follow Taylor's 1949 view that "the most effective form of stating goal is to express the expected student behavior and the behavioral contents."Drawing on the experience of ignoring the students' ability to apply knowledge due to the linear cumulative structure in the 1956 version and draws lessons from the findings of psychology field on studies, it reclassifies educational goals into two dimensions: the one is the "knowledge" dimension, and the other is the "cognitive process" dimension. As shown in Table 1, knowledge dimension mainly assists teachers in differentiating what to teach and the dimension of cognitive process mainly helps teachers to clearly promote the process of students' mastery and application of knowledge. The knowledge dimension refers specifically to the classification of knowledge and is divided into four categories: factual knowledge, conceptual knowledge, procedural knowledge, and metacognitive knowledge.

Factual knowledge is at the bottom of knowledge classification. It refers to the long-term basic knowledge and some fixed symbols in a discipline. Each symbol has its own unique meaning. It includes some proper nouns and details and elements knowledge representing time, place, and person. Conceptual knowledge includes three sections of theoretical knowledge, schemas, and mental models. Together, they organize and construct specific subject knowledge and link different internal element knowledge in a systematic way, making knowledge more general and abstract and finally helping students build theoretical models and clarify ideas. Procedural knowledge refers to a series of specific knowledge about how to do it. Unlike factual and conceptual knowledge, procedural knowledge represents the knowledge of a process. This process can be a routine connection or a solution to a problem., with a series of steps, such as: skills, techniques, methods and algorithms, etc., and factual and conceptual knowledge is just knowledge of the results. Metacognitive knowledge is a knowledge that represents cognition or consciousness or self-cognition. In the teaching process, metacognitive knowledge also includes some strategic knowledge that students use to learn and think and solve problems, which can be applied to different subjects. Meanwhile, it also includes knowledge of cognitive tasks with different strategic knowledge applications for different situations. Self-knowledge is a very important aspect of metacognitive knowledge. Students master development motivation through self-knowledge, monitor and adjust learning behavior, so as to find a learning method that suits them and promote better learning.

TABLE I. 2001 EdUCATION GOALS ClassificATION IN COGNITIVE DOMAIN - KNOWLEDGE DIMENSIONS

\begin{tabular}{|c|c|}
\hline Category & Definitions and Examples \\
\hline \multicolumn{2}{|c|}{$\begin{array}{l}\text { A. Factual knowledge-The basic elements that learners must know when } \\
\text { they master a subject or solve a problem }\end{array}$} \\
\hline AA. Terminology knowledge & Technical vocabulary, music score \\
\hline $\begin{array}{l}\text { AB. Knowledge of specific details } \\
\text { and elements }\end{array}$ & $\begin{array}{l}\text { Several major sources of energy, } \\
\text { reliable sources of information }\end{array}$ \\
\hline \multicolumn{2}{|c|}{$\begin{array}{l}\text { B. Conceptual knowledge-The relationship between the basic elements that } \\
\text { play a common role in an overall structure }\end{array}$} \\
\hline $\begin{array}{l}\text { BA. Category and classification } \\
\text { knowledge }\end{array}$ & $\begin{array}{l}\text { The form of ownership, the period } \\
\text { of geography }\end{array}$ \\
\hline $\begin{array}{l}\text { BB. Knowledge of principles and } \\
\text { generality }\end{array}$ & $\begin{array}{l}\text { Pythagorean theorem, law of supply } \\
\text { and demand }\end{array}$ \\
\hline $\begin{array}{l}\text { BC. Knowledge of theory, model, and } \\
\text { structure }\end{array}$ & $\begin{array}{ll}\begin{array}{l}\text { Evolution-ism, } \\
\text { structure }\end{array} & \text { parliamentary } \\
\end{array}$ \\
\hline \multicolumn{2}{|c|}{$\begin{array}{l}\text { C. Procedural knowledge-Knowledge of how to do things; the method of } \\
\text { inquiry; the criteria for applying skills;knowledge of algorithms, techniques } \\
\text { and methods }\end{array}$} \\
\hline $\begin{array}{l}\text { CA. Knowledge of specific discipline } \\
\text { skills and algorithms }\end{array}$ & $\begin{array}{l}\text { Skills for drawing with watercolors, } \\
\text { algorithms for integer division }\end{array}$ \\
\hline $\begin{array}{l}\text { CB. Knowledge of specific subject } \\
\text { techniques and methods }\end{array}$ & $\begin{array}{l}\text { Interview skills and scientific } \\
\text { methods }\end{array}$ \\
\hline $\begin{array}{l}\text { CC. Knowledge of identifying when } \\
\text { to use appropriate procedures }\end{array}$ & $\begin{array}{l}\text { Decision on when to use Newton } \\
\text { Second Law }\end{array}$ \\
\hline \multicolumn{2}{|c|}{$\begin{array}{l}\text { D. Metacognitive knowledge(Metacognitive knowledge)- knowledge about } \\
\text { general cognition and self-cognition }\end{array}$} \\
\hline DA. Strategic knowledge & $\begin{array}{l}\text { A means of summarizing the } \\
\text { subject of a unit in a textbook }\end{array}$ \\
\hline $\begin{array}{l}\text { DB. Knowledge about cognitive } \\
\text { tasks, including } \quad \text { appropriate } \\
\text { situational and } \\
\text { knowledge. }\end{array}$ & $\begin{array}{l}\text { Knowledge of cognitive processes } \\
\text { required for various cognitive tasks. }\end{array}$ \\
\hline DC. Self-knowledge & $\begin{array}{l}\text { Knowledge of learning about the } \\
\text { level of oneself }\end{array}$ \\
\hline
\end{tabular}

The dimensions of cognitive process are mainly divided into six categories: memory, understanding, application, analysis, evaluation and creation. A two-dimensional classification table is formed based on knowledge and cognitive processes, as shown in Table 2.According to this classification table, the teaching process is designed, the teaching objectives are determined, the teaching activities are arranged, and the teaching evaluation is designed, and it is filled into the corresponding cross grid. This teaching goal classification tool enables teachers to grasp the accuracy of classroom teaching goals, and can closely carry out teaching activities and learning process evaluations around teaching goals. Meanwhile, it can also be regarded as a platform for communication between teachers. 
TABLE II. TEACHING OBJectives BASED ON KNOWLEDGE Dimension AND COGNITIVE DimENSION

\begin{tabular}{|l|l|l|l|l|l|l|}
\hline \multicolumn{1}{|c|}{$\begin{array}{c}\text { Cognitive Dimension } \\
\text { Knowledge Dimension }\end{array}$} & Memory & Understanding & Application & Analysis & Evaluation & Creation \\
\hline Factual knowledge & & & & & & \\
\hline Conceptual knowledge & & & & & & \\
\hline Procedural knowledge & & & & & & \\
\hline Metacognitive knowledge & & & & & & \\
\hline
\end{tabular}

\section{CONCLUSION}

The original classification of knowledge is divided into declarative and procedural knowledge, and Bloom's revised classification of educational objectives classifies teaching objectives from knowledge dimensions and cognitive dimensions. In the knowledge dimension, knowledge is divided into factual knowledge, conceptual knowledge, procedural knowledge and metacognitive knowledge. In cognitive dimensions, cognitive goals are divided into memory, understanding, application, analysis, evaluation and creation. The new classification of educational goals reflects the new development of classification of knowledge and cognitive goals. The new classification has a more explicit goal setting in the teaching process, and different teaching methods can be used for different teaching activities according to different knowledge, so that teaching requirements will be realized. It provides a new direction for teaching.

\section{REFERENCES}

[1] Zhang Chunxing. Educational Psychology. Zhejiang Education Publishing House. 1998 张春兴. 教育心理学. 浙江教育出版社. 1998

[2] Sheng Qunli. The Two-Dimensional Framework for The Classified Revision of The Bloom's Cognitive Targets.Curriculum, Teaching Material and Method. 2004/09 盛群力. 布卢姆认知目标分类修订的二 维框架. 课程.教材.教法. 2004/09

[3] Huang Ying. The Role of Knowledge Classification in Instructional Design - On Revision of Bloom's Educational Target Classification.Educational Review. 2008/05 黄茑. 知识分类在教学设 计中的作用一一论对布卢姆教育目标分类学的修订. 教育评论. 2008/05

[4] Zhang Yan, Huang Ronghuai. The Enlightenment of the 2001 Edition of Educational Objectives Taxonomy to China's Teaching Reform. China Educational Technology. 2005,(7) 张燕, 黄荣怀. 教育目标分类学 2001 版对我国教学改革的启示. 中国电化教育. 2005,(7) 